\title{
A Sustainable and Resilient Housing Model for Indigenous Populations of the Mosquitia Region (Honduras)
}

\author{
Valeria Gambino $^{1}$, Andrea Micangeli ${ }^{1, *}$, Vincenzo Naso ${ }^{1}$, Emanuele Michelangeli ${ }^{1}$ \\ and Luca Di Mario ${ }^{2}$
}

1 CIRPS, Interuniversity Research Center on Sustainable Development, University of Rome, Via Cavour 256, 00184 Roma, Italy;

E-Mails: valeriagambino81@yahoo.com (V.G.); vincenzo.naso@uniroma1.it (V.N.); emanuele.michelangeli@uniroma1.it (E.M.)

2 CSD, Centre for Sustainable Development, University of Cambridge, Trumpington Street, CB2 1PZ Cambridge, UK; E-Mail: 1d358@cam.ac.uk

* Author to whom correspondence should be addressed; E-Mail: andrea.micangeli@uniroma1.it; Tel.: +39-338-815-3787.

Received: 24 April 2014; in revised form: 15 July 2014 / Accepted: 16 July 2014 /

Published: 4 August 2014

\begin{abstract}
This study develops a sustainable housing model for the Mosquitia region of Honduras, aimed at improving the living conditions of indigenous communities and reducing their vulnerability to the effects of climate change. The improved housing efficiency and resilience will contribute to strengthen sanitation and hygiene, improve the living comfort and reduce environmental impact, particularly focusing on preserving the forest biodiversity. The project was developed following the criteria of environmental, technical, social and economic sustainability to propose a shared model, reproducible by the beneficiaries living in different kinds of Mosquitian ecosystems. Increased building efficiency is obtained through optimization of construction techniques and improvement of materials' performances. The main material of the proposed dwelling is wood, coherently with the "Miskita" tradition; the increase of its durability, which is obtained by proper seasoning and protection from atmospheric agents and parasites, contributes to the optimization of the use of this natural resource and to reducing the impact on deforestation, which threatens forest biodiversity. The data collection campaign, conducted before developing the housing model design and which has aimed at obtaining information on technical and social aspects related to residences' welfare and health conditions, has highlighted the great importance of improving the construction model. Despite the advance
\end{abstract}


in sanitary conditions and the economic level, the data collection campaign revealed that even the most developed communities amongst those visited have been perpetrating substantial construction errors, which reduce the resilience of structures to extreme natural phenomena, such as tropical storms and hurricanes, which frequently affect the Mosquitia region. This unexpected discovery increased the importance of housing model design in order to correct these improper construction techniques and avoid their application in the newly-started village growth.

Keywords: housing model; Mosquitia; Honduras; vulnerability; sustainable; resilient; indigenous; wood

\section{Introduction}

The work conducted implements the experience of the CIRPS (Interuniversity Research Center on Sustainable Development)_Sapienza University of Rome within various UN and Europe Aid Rehabilitation projects in Mesoamerican rural areas [1], for local infrastructures and emergency situations [2,3], particularly within the UNDP Honduran project "Conservation of biodiversity in the indigenous productive landscapes of the Moskitia". This project has a focus on biodiversity conservation, both in the socio-cultural aspect of developing indigenous capacity and improving health conditions, and in the environmental aspect of improving efficiency in the use of forest resources, whose sustainable management is one of the objectives of this UNDP project.

Honduras is currently a Lower Middle Income Country [4], and is one of the countries most at risk of the effects of climate change [5]. In particular, the Honduran Mosquitia, under the administrative department of Gracias a Dios, is an isolated area of about 1,663,000 ha, at risk for recurrent natural phenomena such as tropical storms and hurricanes. This area is less developed than the rest of Honduras and this is reported by De Boer in the publication Conocimiento Indigena en Gestión del Riesgo, in which is fully described the lack of health services, education and infrastructures. The population is mainly composed of Miskito Indians, whose 76,000 members make up $88 \%$ of the Honduran Mosquitia inhabitants. The rest of the population is made up of indigenous Tawakha, Garifuni, and Ladinos (mixed race Spanish speaking immigrants from elsewhere in the country,as stated by UNDP publications). The region has been historically isolated from political, economic and cultural context of the country and there are still no road connections between Mosquitia and the surrounding regions. Nevertheless, the conditions of human development vary significantly between the communities within the area analyzed. As this study shows, human development conditions depend mainly on the level of isolation and access to services and natural resources. Whithin the UNDP Honduran project "Conservation of biodiversity in the indigenous productive landscapes of the Moskitia", communities were classified as river, lagoon, or coastal settlements and some high biodiversity ecosystems like savannah and tropical broadleaved moist forest were identified on environmental context basis.

The location of the communities influences both the exposure to natural phenomena and the level of isolation, which increases vulnerability. The product of exposure and vulnerability determines the risk level associated with natural phenomena for each community [6]. It is important to specify that the 
devastating effects of hurricanes are caused not only by the wind force but also by the ensuing floods that affect the communities in different ways.

The forest resources of the area is another relevant environmental element on which the study has been focusing. They have been indiscriminately used, causing a reduction of their accessibility that, together with the shortage of good quality wood, has led local populations to change their traditional construction methods into new and experimental techniques. An external factor influenced this process: extreme natural phenomena, like hurricane Mitch in 1998, entailed international aid in this isolated area and the indigenous populations came in contact with new construction elements, like nails and zinc sheets. The inclusion of these elements revolutionized their traditional methods and implied same construction errors.

Considering the heterogeneous area, the project has been developed following the environmental, technical, social and economic sustainability to propose a housing model which can be shared and reproduced by every beneficiary community. These elements are pivotal elements to ensure that sustainable engineering solutions are delivered $[7,8]$.

\section{Methods and Materials}

The study of the context, as explained below, focused on understanding the local populations' needs, problems and customs and it considered their positions with respect to possible changes in their construction practices. This approach had the aim to create the conditions for "a shared project" to guarantee long-term sustainability. In this study, the expression "share project" had a double purpose: to create a housing model that is reproducible by communities living in different kinds of Mosquitian ecosystems and that is well-appreciated by population because of its Miskita traditional layout and fulfillment of their needs, publicly expressed in focus groups, fostering discussion between different point of view.

\subsection{Context Analysis}

Inspired by the components of the UNDP Human Development Index, which is a composite statistic of life expectancy, education, and income indices used to rank countries into four tiers of human development, this study has considered the following socio-economic and cultural aspects to analyze the context: the level of education, the sanitation and hygiene conditions, and the living standards of each visited community. More specifically, the study identified different levels of development, according to the following factors:

- Level of education (variable between the sixth and the ninth grade);

- Economic model (subsistence economy, market economy based on local fish trade, or market economy based on integration of the local trade of wood, fish and agricultural products);

- Access to health facilities (presence of health posts or health centers, and distance from the Puerto Lempira hospital);

- Type of toilet used (presence of latrines and bathrooms);

- Available means of transport;

- Presence and type of electric power plants [9];

- Ethnic composition. 


\subsection{Technical Analysis}

Since to design a sustainable housing model it is essential to conduct a gap-analysis between current and "optimized" sustainable construction techniques, the study has tried to understand the local populations' current technical capabilities and construction methods, including traditional ones that they are losing, and to identify achievable margins for improvement by capacity building courses.

Considering development aspects and construction methods known by local population, the study has tried to identify what kind of innovations would have found a widespread consent and a real technical sustainability, both in the layout design and in energy systems and materials use.

The study of the construction materials has been pursued to create an eco-sustainable housing model [10], that looks for innovative solutions using available natural elements and aiming to minimize the supply of industrial products, simplifying the construction process and making it economically more accessible to indigenous communities. At the moment, industrial products which are currently used, like zinc sheet, are available only in the main towns of the region, so in order to get their supplies they have logistical difficulties, due to the lack of roads and means of transport, and low buying power on local market, whose prices are already considerably marked up due to the difficulty of imports into the isolated Mosquitia. The complexity of the supply chain compromises the affordability of building materials and discourages housing maintenance, in addition to its implications on $\mathrm{CO}_{2}$ emissions caused by fuel consumption. Since the economic sustainability pursued by the project mainly depends on construction costs and facilitation of building maintenance, these issues have been carefully considered in choosing the project's building materials.

The improvement of building efficiency is achieved not only by the optimization of construction techniques, but also by improving materials performance for better living comfort and housing durability. The main material for the proposed dwelling is wood, according to Miskita tradition; the increase of its durability, obtained by a proper seasoning and protection from atmospheric agents and parasites (according to the Louisiana State University Agricultural Center publication Procesos de Secados para Evitar Difectoses la Madera Verde) contributes to optimization of the natural resource and to reducing the building impact on deforestation, ensuring the environmental sustainability of the project [11].

\subsection{Data Collection}

Although the field mission is essential to gain primary source of information, the methodology of data collection consisted of several activities, some of them preliminary to the field mission. In order to contextualize the project, interactions with international organizations working in the Mosquitia region was carried on before visiting local communities, such as the following:

- Expert and official communications during four internal meetings of the Environmental and Risk Management Unit of UNDP concerning the project of "Conservation of biodiversity in the indigenous productive landscapes of the Mosquitia";

- Communications with UNDP and NGOs field experts and officers that collaborate in implementing the above-mentioned project;

- Review of secondary data, existing official documentation and NGOs projects in progress to frame the context of the mission by the study of documents on the situation of the Mosquitia and by support from the UNDP staff. 
To collect all the necessary data and interact with local communities, a field mission was carried out in eight communities located in different areas of the Mosquitia. Specifically, the study focused on the Honduran communities of Rumdin, Brus Laguna, Krata, Auratá, Kruta, Pranza, Suhí and Santa Fé, that is a border community on Nicaraguan side. Data collection activities conducted during the field mission can be classified as expressed in the following paragraphs.

\subsubsection{Semi-Structured Interviews with Members of Indigenous Population}

Eight semi-structured interviews with members of the population, one for each visited community, were carried out according to the focus group method. All participants were registered by name, age and sex. The moderator encouraged debate between different points of view: a widely shared opinion generally emerged, but also singular opinions were noted (those supported in other groups were taken into consideration). He always asked about planned issues, firstly those about context and secondly those about housing. The general results indicated a clear main response shared in all communities on the most of issues, with some exceptions (i.e., desired type - latrine or bathroom - and position - annexed or not to the house - of the toilet). These cases were balanced with cross-cutting issues such as economical and technical evaluations.

\subsubsection{Interviews with Key Members and Experts}

Field interviews with key members of the community (leaders, teachers, older persons) and technical personnel engaged in on-going co-operation projects in the area (doctors, biologists, project managers) were carried out. One doctor, two biologists, one forest expert, two logisticians, three teachers and older persons (one for each visited community) were interviewed.

Each interview with an expert was specific to his field of work, and concerned only his specific expertise, with the exception of teachers. In particular, interviews with teachers concerned about children (education level, number of children per class) but also about general perception of social and health aspects. It is important to specify that questions about social and health aspects only aimed to take the cue from their perceptions, which were verified during other data collection activities.

Interviews with older persons were extremely interesting from the technical point of view: they talked about ancestral method of construction (showing listed examples), the decrease of "good" available wood for construction, more resistant type of roof to hurricanes and the reason for construction methods' change in their opinions.

\subsubsection{Home Surveys}

Eight home surveys, one for each community, were carried out in order to evaluate the current dwellings (construction techniques, state of maintenance, layout, used materials, number of inhabitants for each dwelling). Specifically, here follow the main technical aspects detected during this activity:

- How many years ago the home was built

- Kind of used wood

- Current state of parasites' damaging action

- Use of pesticide spray 
- Sun exposure of the more damaged facades

- State of maintenance, verifying if there were some replacements of parts

- Dimensions and perpendicularity of main structure

- Type and durability of roof (they often used to replace it)

- Position of oven (outside, in the corridor, in the kitchen) and visible smoked problem

- Housing layout

This data collection activity includes photographic documentation of each detected dwelling.

\subsubsection{Meetings with Indigenous Associations}

The technician responsible for data collection participated to field meetings with members of the beneficiary associations of sustainable trade projects developed by UNDP and NGOs. These projects' implementation was interesting for our study because they concerned climate change risk management, local biodiversity preservation and reduction of population's vulnerability to extreme natural phenomena.

\section{Results}

The analysis of the visited communities clearly revealed that there are specific context scenarios and different ecosystems. However, the general assessment of communities' development level can be considered fairly homogeneous, with the exceptions of Rumdin and Brus Laguna, respectively lower and upper bounds, diverging from others in all factors mentioned in the context analysis. Sanitation is a typical instance: latrines were used in each community. In some communities, each house had one, in others only the richest families had one, while in Rumdin there were none and in Brus Laguna there were also bathrooms.

The proposed housing model, widely shared among several communities, does not neglect local aspects and ensures sustainability in different contexts with a single design. Considering all the benefits (reduction of vulnerability and environmental impact, and enhancing of the sanitary conditions and living comfort), leeway for improvement is different for each community. This might suggest that the motivation for this project is more valid for the least developed communities, supposing that the more development level is high, the more construction techniques are appropriate. In the Mosquitia region, instead, the technical assessment of existing housings shows that even the more developed communities, despite the improvement of their health and economic conditions, have perpetrated serious construction errors that reduce the structures' resilience to extreme natural phenomena, such as tropical storms and hurricanes. This unexpected discovery increased the importance of housing model design in order to correct these improper construction techniques and avoid their application in the newly-started village growth.

The project sustainability, with its several aspects, has driven every design choice, from the phase of building concept to the construction detail.

In this section, current local construction practices are compared with "ameliorative" solutions designed in the housing model: each problem detected in the current housing is first identified and then the proposed solution is explained. 


\subsection{Materials}

\subsubsection{Detected Problem: Process of Natural Seasoning of the Wood}

The low durability of wood is caused by an improper seasoning process, pests attack and atmospheric agents. The population does not dry the wood for more than one or two weeks, with an exception in the area of the Rio Coco, where wood drying can last up to one month. Wood is therefore used in the building site before its natural drying process is finished. Consequently, the natural process will complete during the first months of the houses life. Since the wood drying process involves volume loss, the board of floor and walls contract creating visible gaps before stabilizing. The quality, durability and inherent properties of wood products, are in fact directly related with the process that the material has undergone. This process causes the visible gaps between the boards that are used to construct both the floor and the walls [12] of the dwelling (Figure 1). Furthermore, the short-led process is not careful enough: cut wood is not protected from rain and sun, and, being in contact with the ground (Figure 2), it absorbs moisture, altering the process of expulsion of its internal water.

Figure 1. Visible gaps between the boards of the walls.

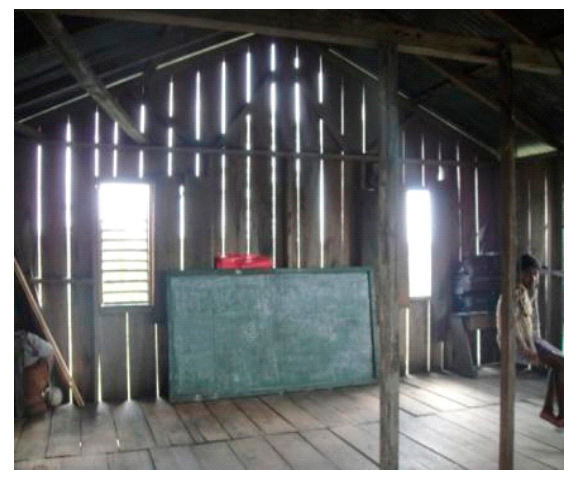

Figure 2. Common method of natural seasoning of the wood.

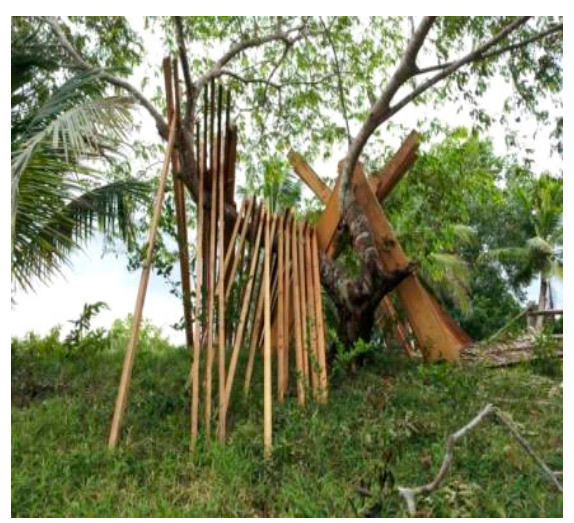

\subsubsection{Recommended Solution}

The cut wood should be protected under a cover or under the first plan of the home, sheltered from rain and sun. Air should be allowed to pass through the boards, by means of spacers (e.g., small branches with a diameter of $4-5 \mathrm{~cm}$ ). Furthermore, the wood should not be directly in touch with the ground, in order to reduce the absorption of moisture, especially in rainy periods. 
The natural process of drying, which ensures that boards' dimensions are stable, can last up to a year, partly depending on the weather conditions. The minimum time recommended to obtain a considerable reduction of the gaps in floors and walls is four months.

Since the parasites begin their damaging action in the first year after cutting, it is very important to treat the wood with a pesticide spray already during the seasoning period.

\subsection{Supporting Structure}

\subsubsection{Detected Problem}

Lack of vertical continuity of modern structure has been noticed, as the pillars are interrupted by the floor beams through an improper connection. It is a serious error that affects the stability of the structure, especially under wind action. In the "ancestral method", the pillars went without interruption from the foundations up to the roof, ensuring proper transfer of the vertical stress (Figure 3), while the horizontal structures were tied to the pillars with bejuco fibers. In modern housing, the difficulty of making the beam-pillar joints with nails has led to interrupting the pillars to insert the beams (Figure 4).

Figure 3. (a) Housing built using the "ancestral method"; (b) Structural detail.

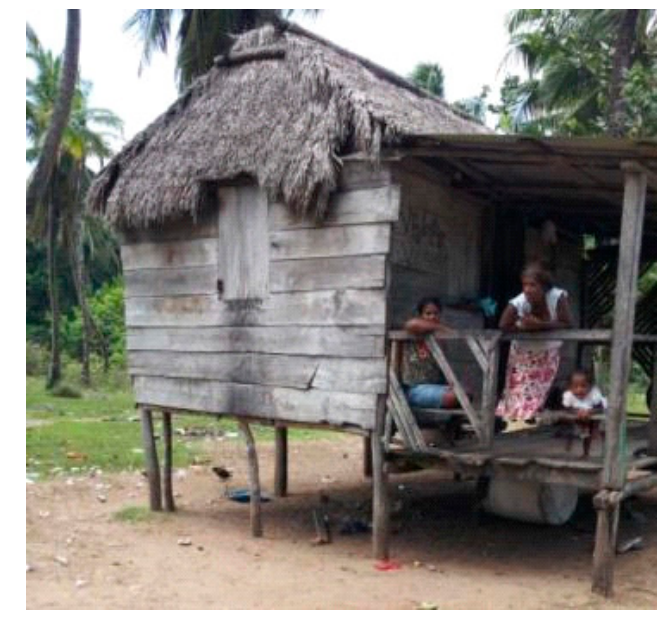

(a)

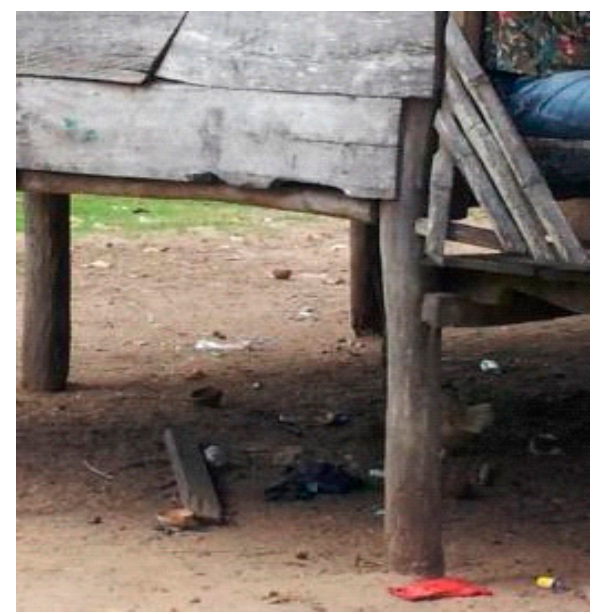

(b)

Figure 4. Structural detail of housing built using the modern method.

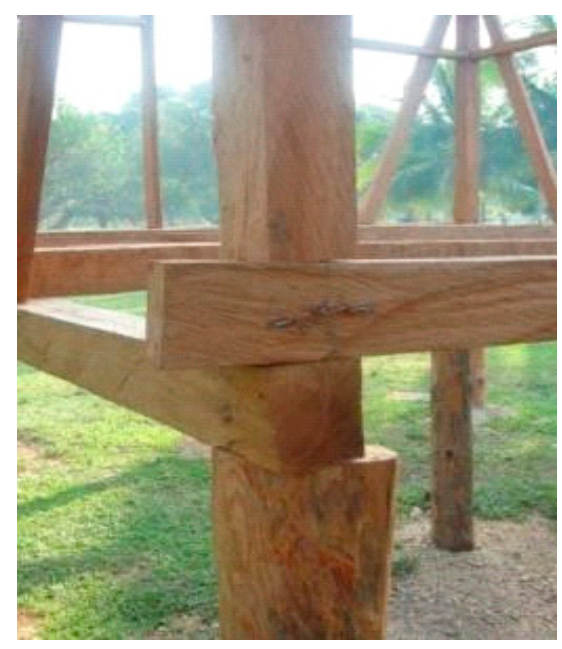




\subsubsection{Recommended Solution}

The pillars that only support the first floor should extend under the level of main beams, while the pillars that also support the roof should be downsized to $1 / 3$ of their section to let the main beams of the floor framework lean on the slot, ensuring vertical continuity from roof to foundations (Figure 5).

Figure 5. Structural details of columns design.

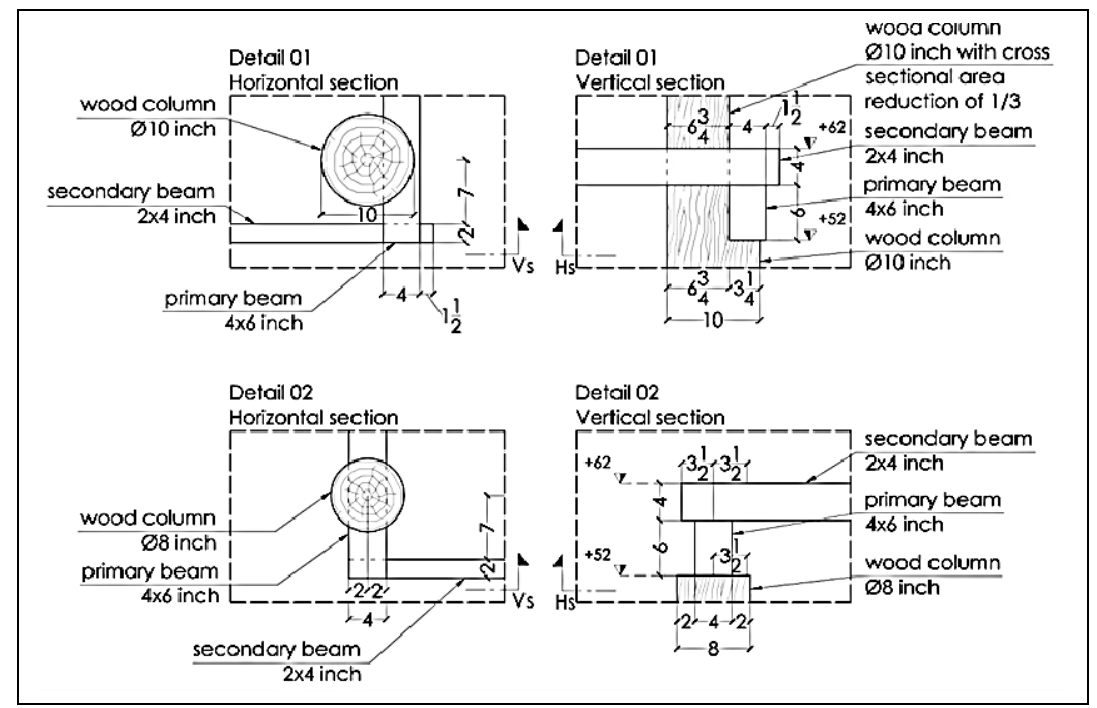

\subsection{Wind Bracings and Resilience to Wind}

\subsubsection{Detected Problem}

One of the objectives of the design is to improve the resilience of Miskita housing in order to reduce the vulnerability of the population. Honduras is in fact the most climate-vulnerable country in the world according to the Global Climate Risk Index 2013, published by Germanwatch [5].

\subsubsection{Recommended Solution}

Wooden wind bracings should be inserted on the north and south sides to improve the stability of the frame structure below the horizontal wind load. Furthermore, two stiffening elements (coverage wind bracings) should be inserted into the structure of the pavilion roof to contain the torsional stresses and keep the shape unaltered. This, coupled with a proper seasoning of the wood as discussed in the preceding paragraphs, increases the resilience, durability and efficiency of the housing model.

\subsection{Roof Covering}

\subsubsection{Detected Problem}

The most widespread type of roof covering is made of zinc sheets, which pose a health risk in case of oxidation: the oxidized zinc sheet can release metal particles in the rainwater, collected by the population for drinking. In addition, the zinc sheet creates condensation at sunrise, which is 
contaminated by the soot deposited by the smoke of wood-burning oven on the kitchen ceiling, and eventually drops on food and utensils (Figure 6).

Figure 6. (a) Six year old roof of a kitchen, made of zinc sheets with visible soot, produced by the smoke of wood-burning oven; (b) Just constructed roof of a kitchen, made of zinc sheets.

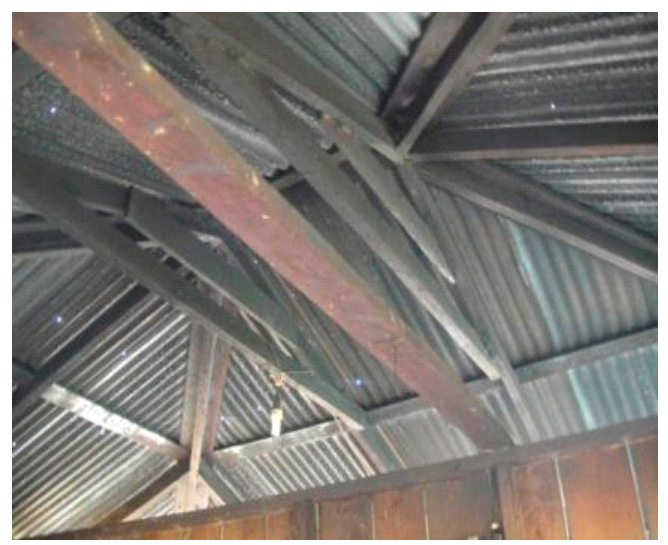

(a)

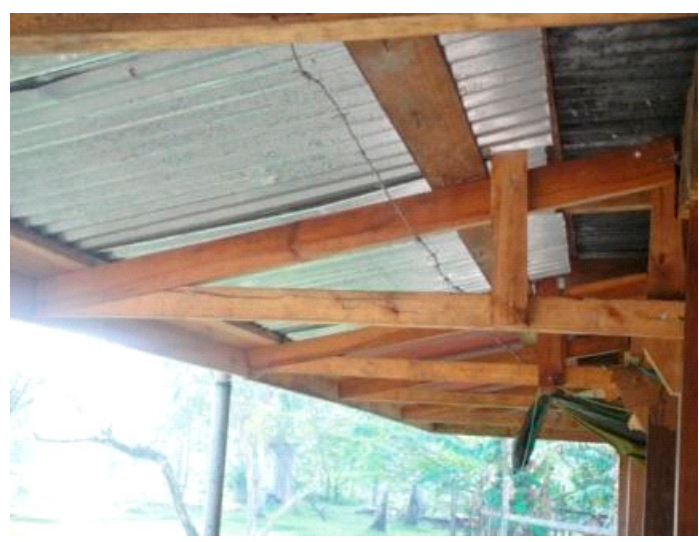

(b)

\subsubsection{Recommended Solution}

The recommended new roof design uses the "Quicha Mejorada" multilayer technique [13,14]. It's made of hollow bamboo canes, with an external diameter of about $2 \mathrm{~cm}$, laid perpendicularly to the supporting wood structure. A clay-based mixture of local soil is thrown on the bamboo canes to form a layer of $2.5 \mathrm{~cm}$. The outer layer is a mixture of sand and cement constituted by a rate 1 to 5 .

The inner layer, that is necessary to protect the canes from insect attacks, is constituted by of a mixture of cement, sand and gypsum, with a thickness of $1.5 \mathrm{~cm}$. The sand is supplied from the river bed and is commonly used in reinforced concrete buildings by the municipality. On the other hand, cement and gypsum must be bought in local markets (Figure 7). This system has several advantages on zinc sheet:

- It is more resistant against the wind action because the bamboo canes are bound to the supporting structure by nails and strings made of bejuco and the outer layers create a smooth coating, reducing the risk of roof overturning;

- It improves living comfort because of its lower thermal transmittance, reducing overheating;

- It improves housing salubrity because it avoids rainwater contamination and condensation on kitchen ceilings, thanks to its greater thermal inertia and lower thermal transmittance;

- It improves fire safety because it decreases the propagation speed of fire thanks to its fireproof inner layer;

- It pursues a greater sustainability because the only material not found in the natural environment is cement, that is cheaper and easier to transport than zinc sheet; considering that local people used to move on foot, by pipante (Miskita canoe) or by bike (rare), a cement sack can be transported without looking for an off-road vehicle. 
Figure 7. Detail of roof covering design.

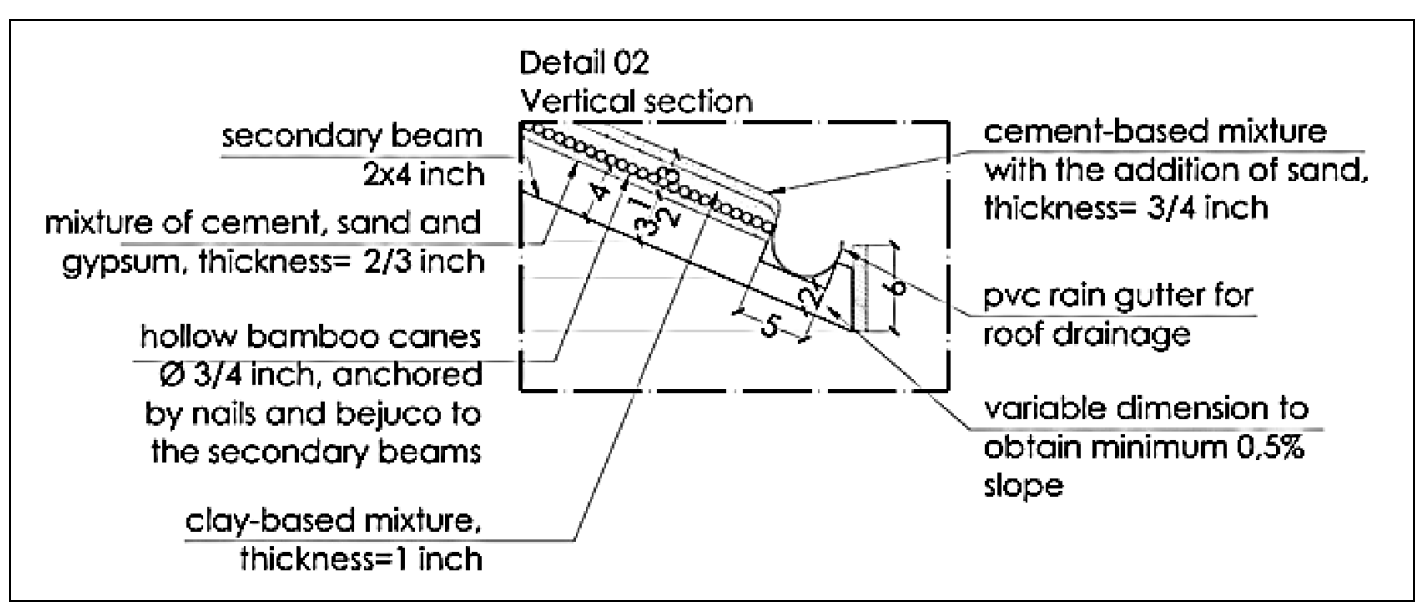

\subsection{Stairs}

\subsubsection{Detected Problem}

Many stairs from the ground level to the first floor are subject to structural failure, in some cases due to the undersizing of structural elements and in others to the lack of foundation (Figure 8.). This problem makes the structure unstable and dangerous, as confirmed by numerous elderly and child domestic accidents reported during focus groups.

Figure 8. (a) Stairs; (b) Stairs built using the modern method.

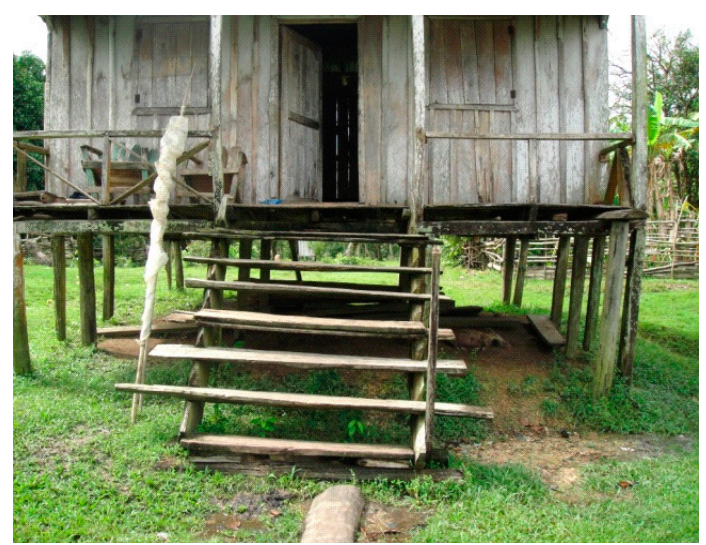

(a)

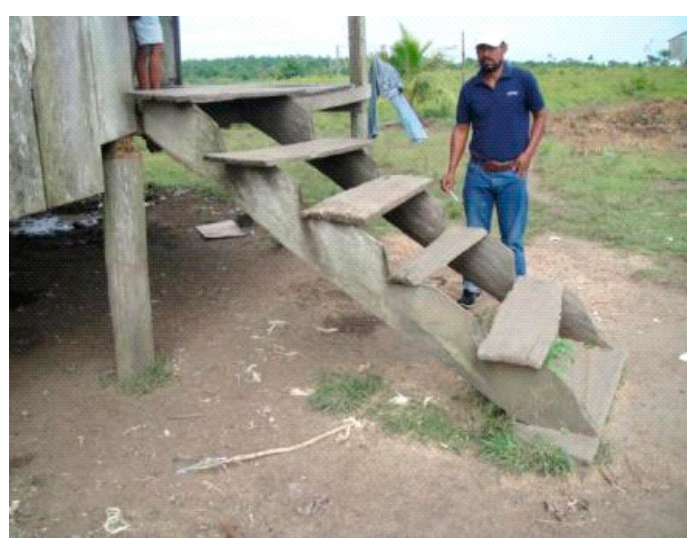

(b)

\subsubsection{Recommended Solution}

An adequate dimensioning of the stairs' structural elements is foreseen in the project. Furthermore, a foundation is provided to ensure the proper transfer of the vertical stress to the ground. It can be realized in a very easy way and only with natural and locally available materials. This simple foundation balances the beams stress and reduces asymmetric structural failures that are the main cause of sloping and unstable stairs (Figure 9). 
Figure 9. Detail of stairs foundation design.

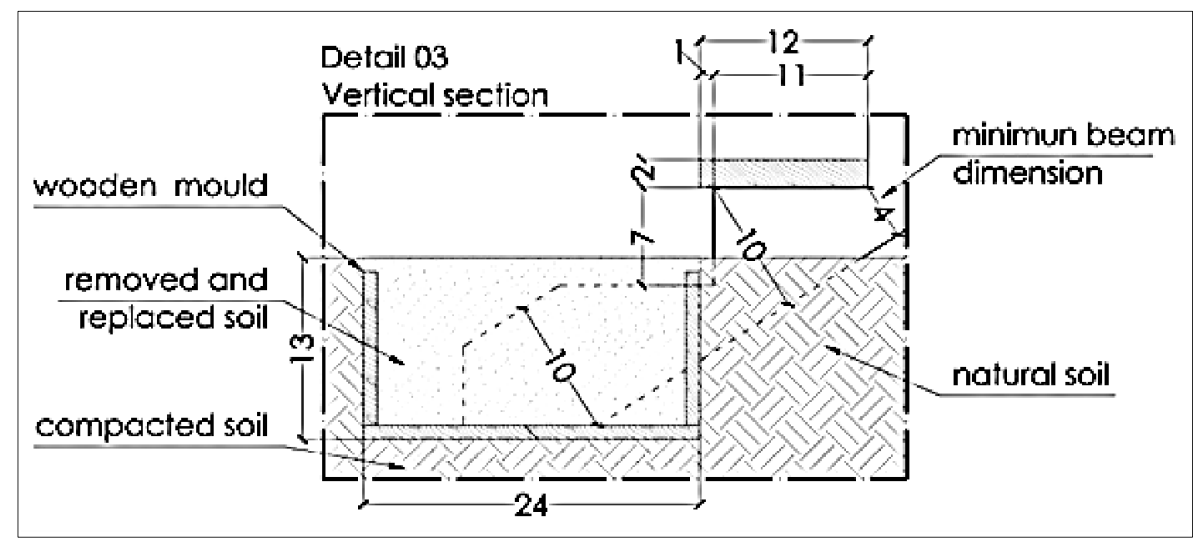

\subsection{Vertical Supporting Structure of Facade System}

\subsubsection{Detected Problem}

In current dwellings the vertical structure of the facade supports both the wall boards and the roof edge beams. This structural scheme, although theoretically acceptable, is strictly connected to the lack of vertical continuity of the structures (see "Supporting structure" section). For the vertical structures to act as facade covering supports, they need to be tightly spaced to withstand the wind force; at the same time, if they were to support the roof and guarantee a proper stress transfer, they should not be interrupted at the first floor level (see "Supporting structure" section). Therefore, the only correct way of carrying out both functions with this structural scheme would be to create a dense mesh of perimeter pillars from the foundation to the roof without interruption, but this would not be an economically sustainable solution for the beneficiary populations.

\subsubsection{Recommended Solution}

The roof structure should be supported by the main pillars that are continuous from foundation to roof, while the vertical structure of the facade is studied as a secondary frame to withstand the horizontal wind force. In addition, the vertical structure of the facade should be connected directly to the secondary beams of the roof to reduce the risk of roof overturning (Figure 10).

Figure 10. Detail of facade vertical supporting structure design.

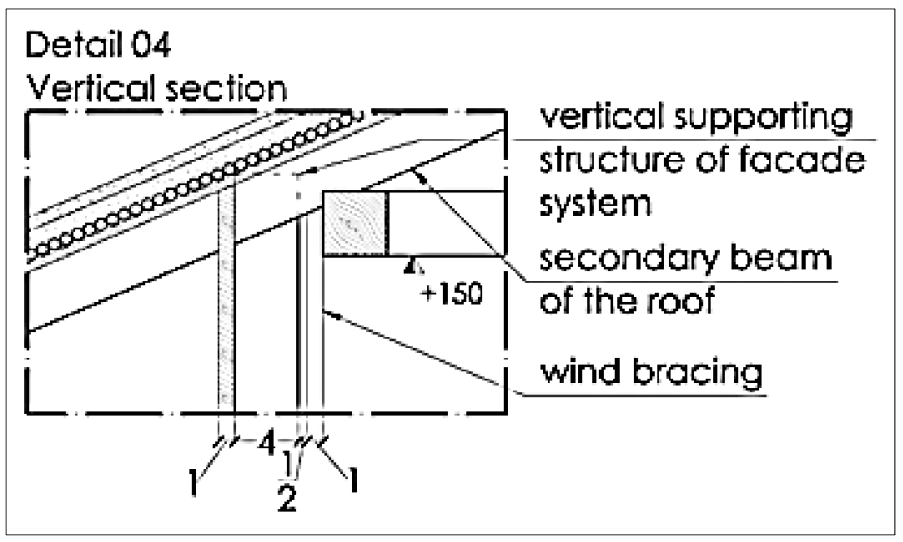




\subsection{Wooden Floor and Facade Covering}

\subsubsection{Detected Problem}

Both architectural elements are affected by gaps that visibly separate a board from another up to 3-4 cm, allowing the entry of water, cold and insects (Figure 11). In addition, in two of the visited communities, it emerged that thieves could easily pierce sacks of rice and seeds and empty them through the gaps. These gaps are caused by an incorrect process of natural seasoning of wood and by laying the boards too early (see the "Process of natural seasoning of the wood" section).

Another problem detected on the external walls is the degradation of the boards.

In most cases, the wall boards are vertically woven. This implies that to replace a damaged board it needs to be removed or cut, with related problems of hooking up old and new pieces. To understand the practical problems of this work that could appear simple, the reader should bear in mind that in most cases the only available tools are a machete and some nails.

Figure 11. (a) Wooden facade covering; (b) Detail.

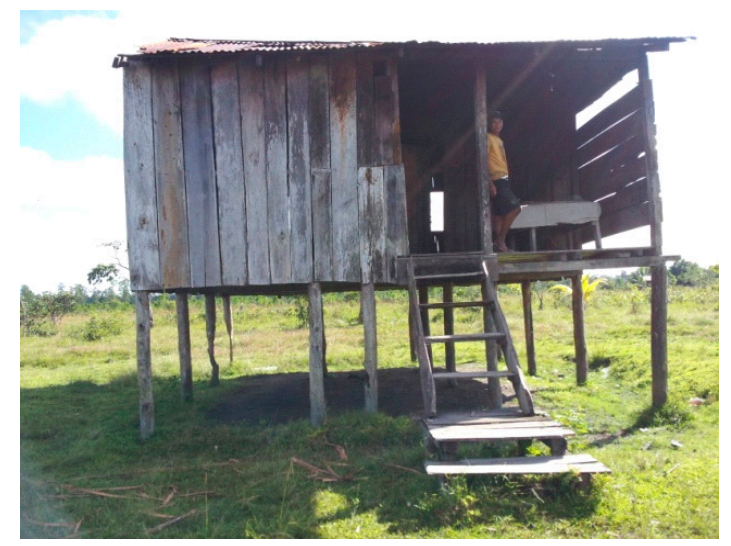

(a)

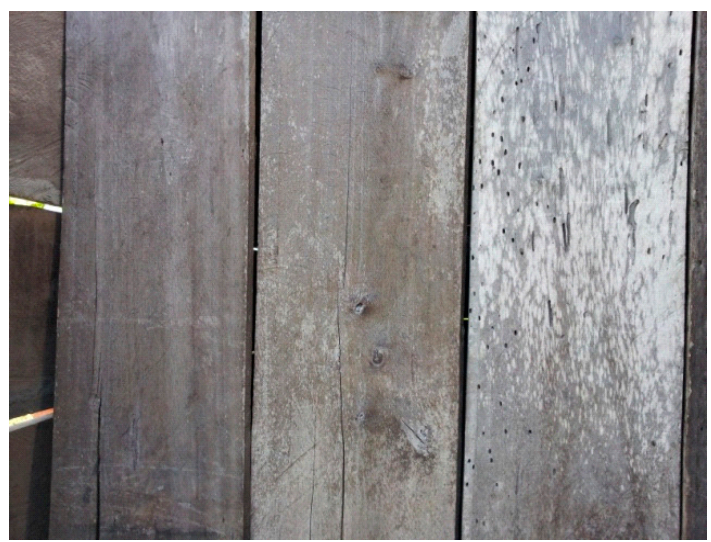

(b)

\subsubsection{Recommended Solution}

The first measure is following the recommended solution on the proper seasoning process (see "Process of natural seasoning of the wood" section). Furthermore, the boards should be cut with an angle of $45^{\circ}$ (a groove interlocking would be even better, but this can only be done with special saws, available only in some communities) in order to reduce the amplitude of the gaps due to a further contraction of the wood after laying.

In order to reduce the maintenance problems due to the degradation of the wooden facade covering, the boards should be horizontally woven (Figure 12), since the action of the atmospheric agents affects the lower part of the facade most. In the prescribed solution, the maintenance is easier and cheaper, as it is possible to replace the damaged boards only, starting from the bottom and up to the necessary level. 
Figure 12. Detail of wooden floor and facade covering design.

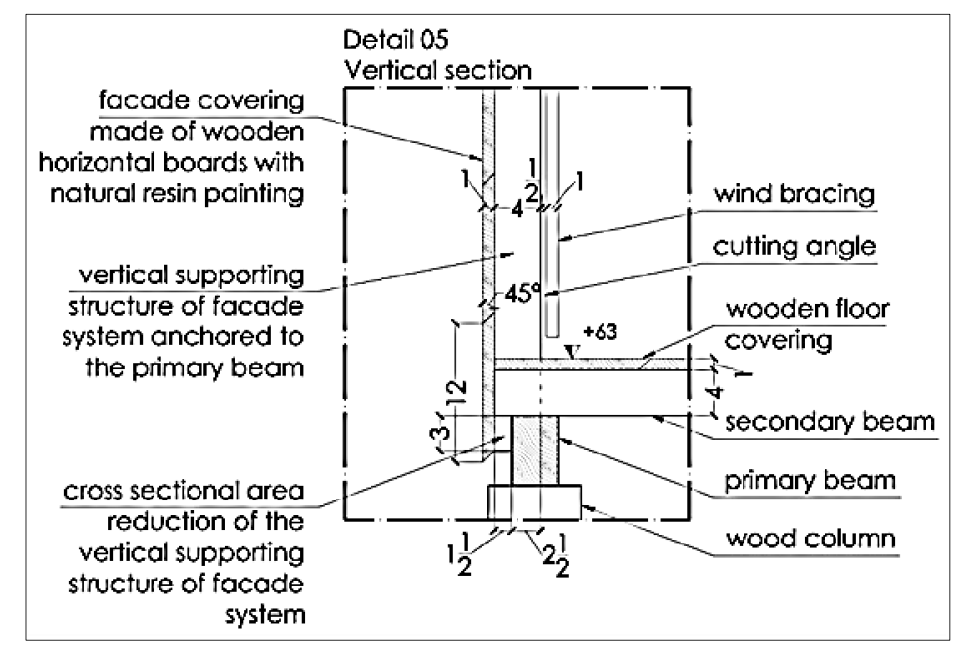

\subsection{Wood-Burning Oven and Floor of the Kitchen}

\subsubsection{Detected Problem}

The main problem of the kitchen is the smoke generated by the wood-burning oven that is not expelled by means of adequate ventilation. In addition, there is a high fire risk that, according to focus groups' reports, generally flares up from the wood-burning oven due to the inattention of children. From the investigation carried out to identify which location the populations prefer for their kitchen, discordant views have emerged. Some prefer the kitchen annexed to the house, because it is more convenient and easier to monitor stored food, but only if the smoking problem is solved. Others prefer the kitchen placed in a different building, near the rest of the house, to reduce the risk of fire propagation and the smoke problem. However, many of them admit not to have enough economic resources to realize a separate building. Both solutions have been found in the communities.

\subsubsection{Recommended Solution}

The designed solution sets the kitchen annexed to the rest of the house, but separated from it by an outside corridor, respecting Miskita tradition. This choice has been affected by the following assessments: a kitchen placed in a different building would not be economically sustainable for everybody; $2 / 3$ of persons that prefer the kitchen placed in a different building explain their preference because of the smoke problem and, secondly, because of the risk of fire propagation. The project attempts to reduce these problems and considers only solutions which are economically sustainable for most of the population.

In order to solve the smoke problem it is necessary to improve the wood-burning oven and insert an exhaust pipe. It is important to respect all the technical conditions for a good draught: adequate size and length of the exhaust pipe with a vertical or slightly inclined direction, windproof chimney, smooth material for the interior of the pipe to reduce hot air friction and facilitate air flow (pipes made of PVC accessible to the communities should be fine), and stokehole wider than its height to facilitate a good combustion and to avoid draught problems. 
In order to reduce the fire risk, a different floor for a part of the kitchen has been designed: the wooden board level is lowered in the area around the wood-burning oven and the obtained level drop is filled with a mixture of natural clay, sand, water and straw, sun-dried after installation (Figure 13.). The distance between secondary beams is decreased in this area to compensate for their reduced section, necessary to obtain the coplanarity of the different kinds of floor.

Figure 13. Detail of kitchen floor design.

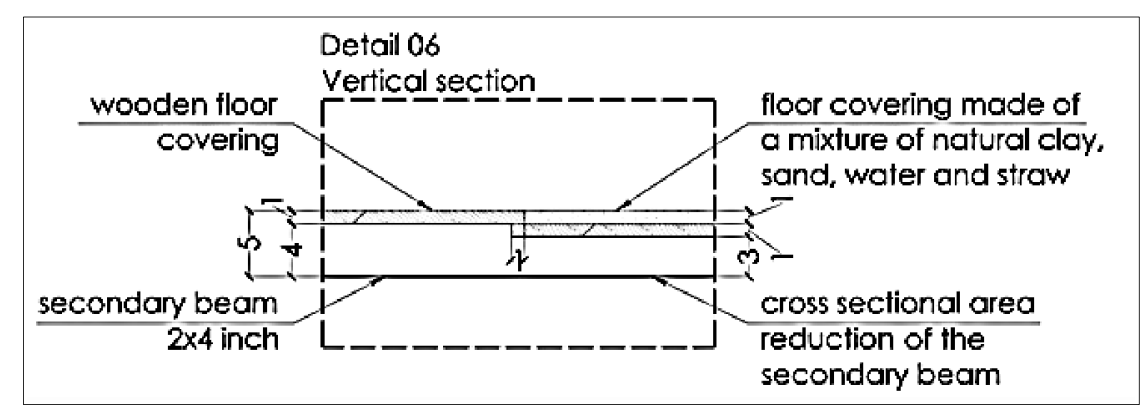

\section{Discussion}

The project proposes a sustainable solution from the technical, social, economic and environmental point of view and it is framed in the safeguard policies of Mosquitian forests.

Recommended solutions may be recaped focusing on their impact on the current context in order to explain their sustainability and long term effects:

- Improving wood durability (see Section 3.1), through a correct seasoning process and protection from parasites, there is apositive consequence on structural stability, on health conditions (solving the problem of gaps between the boards, the entry of water, cold and insects is decreased), on economic aspects (prolonging buildings' life and reducing maintenance costs), and on forest protection (decreasing the demand of wood);

- Solving the problem of lack of vertical continuity (see Sections 3.2 and 3.6) and inserting wind bracings (see Section 3.3) the structure improves its resilience to extreme natural phenomena, therefore the housing model contributes to the general goal pursued by international cooperation: reduction of population's vulnerability;

- Substitution of the roof covering (see Section 3.4) made of zinc sheets with a natural multilayer technique preserves healthy (avoiding dangerous consequences derived from zinc oxidation) and reduces building construction costs;

- Adequate dimensioning of the stairs' structural elements (see Section 3.5) improves housing safety (decreasing risk of domestic accidents);

- Suggesting that the boards should be horizontally woven and cut with an angle of $45^{\circ}$ (see Section 3.7), maintenance costs of wooden floor and facade covering are reducing, while health condition is improving (solving the problem of gaps between the boards, the entry of water, cold and insects is decreased);

- Kitchen design (see Section 3.8) improves both health condition (reducing the smoke problem related to the wood-burning oven) and housing safety (decreasing fire risk). 
Energy innovations were excluded because it would not have been sustainable for all the communities without an external technical and financial support coupled with capacity building for the supply management. Therefore, a future development of this project is highly recommended in order to implement energy supply from renewable sources. In this case, the feasibility study should be reviewed taking into consideration the above mentioned sustainability aspects.

A future integration of renewable energy in this housing model is extremely interesting, for instance using storage integrated solar collectors [15]. Keeping in mind that the project aims at improving living conditions and reducing the vulnerability to natural disasters of the indigenous populations, the fieldwork has shown how much the housing study is connected with the energy issue. It does not refer to the common relationship between "house and energy system" [16], but to the margin of action to reduce the vulnerability of populations: the more a proper constructed house can increase a person's safety from environmental phenomena, the more a renewable and sustainable energy system can contribute to strengthening local economy, in order to enable affected people to cope with a post-disaster situation. In this way, the overall vulnerability can be reduced by improving the resilience of the buildings and strengthening the socio-economic system.

\section{Conclusions}

This housing model for indigenous communities of the Mosquitia region has been developed with the specific objective of reducing the population's vulnerability to extreme natural phenomena, reducing environmental impact, enhancing health conditions and improving living comfort, always taking sustainability into account. The approach applied to develop the housing model is firstly based on a deep knowledge of the context and local construction techniques. The field mission is the core of this analysis process and it reveled two important lessons learned in this study: lost traditional methods should be understood, looking for lasted examples and collecting older persons' memories, in order to evaluate whether and why something good has been lost; only an assessment focused on local populations' needs, desires and capabilities can guarantee the project success and its long-term sustainability. In fact, the project started from the study of local traditional construction methods, reevaluating those technically valid that are being lost due to the introduction of industrial products, that have difficult maintenance, compromise the population's health and have a high impact on the protected ecosystem.

The importance of applying this housing model is especially relevant for transferring technical knowledge and expertise in developing countries, respecting local biodiversity. This process is gradual and its success mostly depends on the assessment of what the beneficiaries are ready to accept and what kind of support they need. Since an overly-ambitious project can sometimes be counter-productive, the explained housing model proposes only technical solutions that indigenous populations are able to realized using local materials and being supported by capacity building courses.

\section{Acknowledgments}

Thanks to Michele Pagano di Melito, Marco Ricci, for the contribution to the writing of this article. 


\section{Author Contributions}

The present paper is the result of the free, full and equal cooperation among all the Authors, who had the following roles: Valeria Gambino, Project Leader and Coordinator of the field work, was the Corresponding Author, recollected data in the Moskitia Region and in Honduras in general, supported by Andrea Micangeli and Emanuele Michelangeli; Vincenzo Naso, Team Leader, supervised the whole work; Luca Di Mario supervised the scientific aspects of the whole paper contents. All authors approved the final manuscript.

\section{Conflicts of Interest}

The authors declare no conflict of interest.

\section{References and Notes}

1. Micangeli, A.; Cataldo, M. Micro Hydro in Emergency Situations: A Sustainable Energy Solution at La Realidad (Chiapas, Mexico). In Handbook of Sustainable Engineering; Springer: Dordrecht, The Netherlands, 2013.

2. Micangeli, A.; Michelangeli, E.; Naso, V. Sustainability after the thermal energy supply in emergency situations: The case study of Abruzzi Earthquake (Italy). Sustainability 2013, 5, 3513-3525.

3. Grego, S.; Micangeli, A.; Esposto, S. Water purification in the Middle East crisis: A survey on WTP and CU in Basrah (Iraq) area within a research and development program. Desalination 2004, 165, 73-79.

4. DAC List of ODA Recipients Effective for reporting on 2012 and 2013 flows. Available online: http://www.oecd.org/dac/stats/DAC\%20List\%20used\%20for\%202012\%20and\%202013\%20flows.pdf (accessed on 10 December 2013).

5. Harmeling, S.; Eckstein, D. Global Climate Risk Index 2013, Who suffers most from extreme weather events? Weather-related loss events in 2011 and 1992 to 2011, Germanwatch. Available online: http://germanwatch.org/fr/download/7170.pdf (accessed on 23 July 2014).

6. Coburn, A.; Spence, S.; Pomonis, A. Vulnerability and Risk Assessment. Available online: http://worldbank.mrooms.net/file.php/356/2234/Introduction\%20Reading\%20-\% 20VulnerabilityAndRiskAssessmentGuide.pdf (accessed on 23 July 2014).

7. Fenner, R.A.; Ainger, C.; Cruickshank, H.; Guthrie, P. Widening engineering horizons: Addressing the complexity of sustainable development. P. I. Civil Eng. Eng. Su. 2009, 162, 177-178.

8. Fowler, K.M.; Rauch, E.M. Sustainable Building Rating Systems Summary; PNNL-15858; Pacific Northwest National Laboratory, US Department of Energy: Richland, WA, USA, 2006.

9. European Commission (EU). Increasing the Impact of EU Development Policy: An Agenda for Change; EU: Bruxelles, Belgium, 2011.

10. Berardi, U. Clarifying the new interpretations of the concept of sustainable building. Su. Cities Soc. 2013, 8, 72-78.

11. Ding, G.K.C. Sustainable construction-The role of environmental assessment tools. J. Environ. Manag. 2008, 86, 451-464. 
12. Peraza Sánchez, F. Protección preventiva de la madera; Asociación De Investigación Técnica De Las Industrias De La Madera Y El Corcho: Madrid, Spain, 2001. (In Spanish)

13. Hahn, T.J. Research and solutions: LEED-ing away from sustainability: Toward a green building system using nature's design. Sustain. J. Rec. 2008, 1, 196-201.

14. Romero Zeballos, G. Construyendo viviendas con Quincha mejorada-Tecnología de Mitigación de Riesgos. Alexis Vilchez Aguilar: Lima, Peru, 2008. (In Spanish)

15. Borello, D.; Corsini, A.; Delibra, G. Evangelisti, S.; Micangeli, A. Experimental and computational investigation of a new solar integrated collector storage system. Appl. Energ. 2008, 97, 982-989.

16. Dell'Era, A.; Zuccari, F.; Santiangeli, A.; Fiori, C.; Micangeli, A.; Orecchini, F. Energy optimization and layout of a membrane-free OSEC system for the hypochlorite self-production in Developing Countries. Energ. Conver. Manag. 2013, 75, 446-452.

(C) 2014 by the authors; licensee MDPI, Basel, Switzerland. This article is an open access article distributed under the terms and conditions of the Creative Commons Attribution license (http://creativecommons.org/licenses/by/3.0/). 